\title{
Electrochemical behaviour of copper(II) at a hanging mercury drop electrode
}

\author{
Ahmed A. Al-Owais ${ }^{\mathrm{a}}$, Ibrahim S. El-Hallag ${ }^{\mathrm{b}, *}$ \\ a Chemistry Department, Faculty of Science, King Saud University, Riyadh, Saudi Arabia \\ b Chemistry Department, Faculty of Science, Tanta University, Tanta 31527, Egypt \\ *Corresponding author, e-mail: i.elhallag@yahoo.com
}

Received 18 Nov 2014

Accepted 10 Apr 2016

\begin{abstract}
The electrochemical properties of $\mathrm{Cu}$ (II) ions were studied in $0.1 \mathrm{M} \mathrm{KNO}_{3}$ at a hanging mercury drop electrode using cyclic and convolutive voltammetry in addition to chronoamperometry and chronopotentiometry methods. The $\mathrm{Cu}$ (II) ions consumed two electrons in two steps to form monovalent $\mathrm{Cu}$ (I) ions and Cu metal followed by a process of amalgam formation. The rates of both electron transfer steps were found to be quasi-reversible. Digital simulation was used to verify the electrode pathway and to determine and confirm the electrochemical parameters of the reductive process of bivalent $\mathrm{Cu}(\mathrm{II})$ ions.
\end{abstract}

KEYWORDS: convolutive voltammetry, electrode pathway, electrochemical parameters, Cu metal

\section{INTRODUCTION}

The use of copper compounds in medical application is well established ${ }^{1}$. The immune system and thyroid gland health depend on copper level and any shortage in copper level may lead to the development of hyperthyroidism. In several biological reactions, copper is important as an electron donor. Copper deficiency is treated by taking cupric sulphate at doses up to $0.1 \mathrm{mg} / \mathrm{kg}$ daily. Some benefits of copper gluconate have been used in the treatment of osteoporosis, cardiac arrhythmia, wound healing, vascular disease, osteoarthritis, reducing high cholesterol levels in humans and rheumatoid arthritis.

After coordinating with metal ions, copper can play an important role in altering the pharmacological properties of known drugs ${ }^{2}$. Drugs containing metal compounds such as antidiabetic, antiinflammatory, antimicrobial, antimanic, antiulcer, and antiparasitic, antihypertensive agents have already been reported ${ }^{3}$. About $30-40 \%$ of all known proteins are metalloenzymes which need traces of metal cofactors such as Fe, Cu, Zn, Ni, Mn for their proper folding into an active $3 \mathrm{D}$ structure during biological processes ${ }^{4,5}$.

In buffer solution of different $\mathrm{pH}$, the volumetric measurements of $\mathrm{Cu}$ (II) in the presence of L-phenylalanine (Phe) and aspartic acid (Asp) has been carried out. The effect of scan rate and variation of Phe or Asp concentrations were demonstrated. In the presence of Phe and Asp, Cu(II) has been found to undergo two cathodic peaks coupled with twostep two-electron transfer anodic reaction ${ }^{6}$.

Copper(II) salen undergoes a three-step reduction at a glassy carbon cathode, in dimethylformamide containing tetramethylammonium tetrafluoroborate; the first peak is due to the reduction of copper(II) to copper(I), the second one is due to the reduction of copper(I) to copper metal, and the third voltammetric peak arises from reduction of the dianion salen ${ }^{7}$. It is established that at low values of $\mathrm{pH}, \mathrm{Cu}$ (II) was reduced electrochemically via two-step reduction mechanism, while at high $\mathrm{pH}$ it proceeds via one-step process ${ }^{8}$. Also, the electrochemical reduction of $\mathrm{Cu}$ (II) ion has been studied with various supporting electrolytes in acidic and basic media 9,10 .

To the best of our knowledge, there is a shortage of studies dealing with the electrochemical behaviour of $\mathrm{Cu}$ (II) ions via convolutive voltammetry, chronoamperometry and chronopotentiometry. The present work therefore investigated the electrochemical behaviour of $\mathrm{Cu}$ (II) ions in aqueous $\mathrm{KNO}_{3}$ solution as a supporting electrolyte. The electrochemical parameters were determined and the electrode pathway was suggested and verified using a digital simulation method.

\section{MATERIALS AND METHODS}

\section{Chemicals}

To prepare the solutions, we used $\mathrm{CuSO}_{4}$ and $\mathrm{KNO}_{3}$ reagents (analytical grade from Fluka). Triple dis- 
tilled water was used as a solvent. The experiments were carried out in samples of $\mathrm{Cu}$ (II) at the concentration $2.5 \times 10^{-4} \mathrm{M}$ in $0.1 \mathrm{M} \mathrm{KNO}_{3}$ as supporting electrolyte. The solutions were deaerated using nitrogen. The gas was passed over the solutions during the measurements.

\section{Apparatus}

A polarographic analyser (from EG \& G) with a cell for cyclic voltammetry (CV) was used to conduct the experiments. The data of residual current were also stored and subtracted from the captured data set, minimizing the effects of double layer charging current. The measurements were performed with an electrode assembly Model 303A, with an HMDE (area $=2.61 \times 10^{-2} \mathrm{~cm}^{2}$ ) as working electrode, $\mathrm{Ag} / \mathrm{AgCl}$ as reference electrode, and a $\mathrm{Pt}$ wire as auxiliary electrode. CV experiments were investigated at scan rates in the range $0.02-5 \mathrm{~V} / \mathrm{s}$. Generation of the theoretical cyclic voltammograms was carried out by digital simulation using EG \& G CONDESIM and finite difference techniques ${ }^{11}$. For the simulation program, the algorithms were coded and executed into the package supplied by EG \& G.

\section{RESULTS AND DISCUSSION}

\section{Cyclic voltammetry measurements}

The electrochemical behaviour of $2.5 \times 10^{-4} \mathrm{M}$ of the $\mathrm{Cu}$ (II) ions was studied in detail using cyclic voltammetry in $0.1 \mathrm{M}$ aqueous solution of $\mathrm{KNO}_{3}$, at scan rates in the range of $0.02-5 \mathrm{~V} / \mathrm{s}$. Fig. 1 shows a typical response of $\mathrm{Cu}$ (II) at scan rate of $0.1 \mathrm{~V} / \mathrm{s}$ after subtracting the background and correcting the

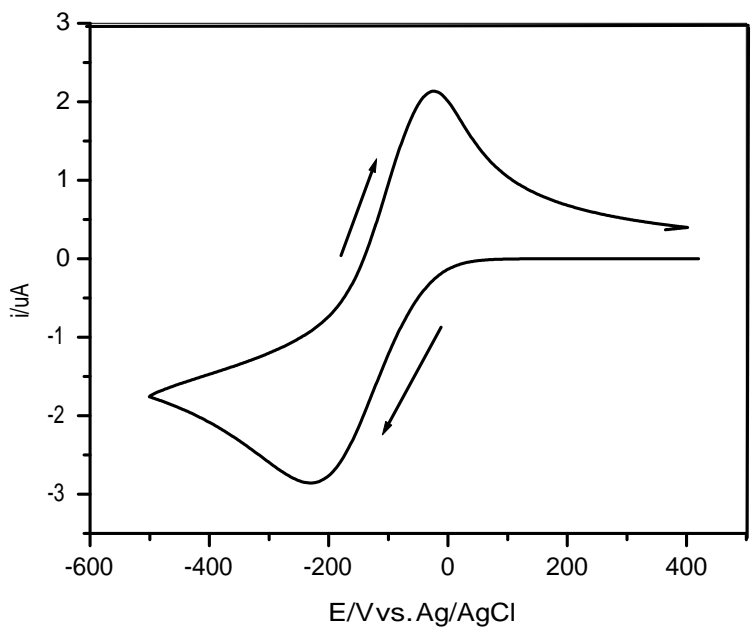

Fig. 1 Cyclic voltammogram of $2.5 \times 10^{-4} \mathrm{M}$ of $\mathrm{Cu}(\mathrm{II})$ in $0.1 \mathrm{M} \mathrm{KNO}_{3}$ at a scan rate of $0.1 \mathrm{~V} / \mathrm{s}$.
Table 1 Values of wave characteristics of cyclic and deconvoluted voltammograms of $\mathrm{Cu}(\mathrm{II})$ ion at various scan rates.

\begin{tabular}{lcccc}
\hline $\begin{array}{l}\text { Scan rate } v \\
(\mathrm{~V} / \mathrm{s})\end{array}$ & $\begin{array}{c}E_{\mathrm{p}} \\
(\mathrm{mV})\end{array}$ & $\begin{array}{c}E_{\mathrm{p}}-E_{\mathrm{p} / 2} \\
(\mathrm{mV})\end{array}$ & $\begin{array}{c}\Delta E_{\mathrm{p}} \\
(\mathrm{mV})\end{array}$ & $\begin{array}{c}W^{\mathrm{p} / 2} \\
(\mathrm{mV})\end{array}$ \\
\hline 0.1 & 230 & 124 & 212 & 187 \\
0.2 & 251 & 136 & 240 & 211 \\
0.5 & 289 & 143 & 273 & 234 \\
1 & 342 & 163 & 303 & 251 \\
2 & 366 & 187 & 337 & 278 \\
5 & 462 & 201 & 354 & 292 \\
\hline
\end{tabular}

uncompensated resistance. The cyclic voltammogram exhibits one broad cathodic peak coupled with one anodic peak.

It was found that the height of the cathodic and the anodic peaks increased as the scan rate increased, and the position of the cathodic and the anodic peaks depended on the scan rate. The variation in peak separation $\left(\Delta E_{\mathrm{p}}=113-462 \mathrm{mV}\right)$ in the studied range of the scan rate indicates that the rate of $\mathrm{Cu}$ (II) ion reduction proceeded moderately fast ${ }^{12}$.

This means that the first step produces a univalent copper ion $\mathrm{Cu}(\mathrm{I})$ that accepts another electron to form copper metal which then combines with $\mathrm{Hg}$ to form copper amalgam. The ratio of the backward peak current to the forward one is less than unity, confirming the formation of copper amalgam ${ }^{13}$. It was found that the measured values of peak width, $E_{\mathrm{p}}-E_{\mathrm{p} / 2}$, increased with the increasing scan speed (Table 1), confirming the quasi-reversibility of the rate of electron transfer. The variation of peak separation $\left(\Delta E_{\mathrm{p}}\right)$ and the peak broaden with sweep rate was consistent with that of an overall two sequential moderate fast electron transfer reaction ${ }^{13}$.

The redox potential $\left(E^{\bullet}\right)$ values of the two moderate fast charge transfer were determined from generated cyclic voltammograms. Accordingly, the electrode reaction might be suggested to proceed as two sequential quasi-reversible Faradaic processes followed by amalgam formation. The values of the first and second standard heterogeneous rate constants $\left(k_{1}^{\ominus}\right.$ and $k_{2}^{\ominus}$ ) of electron transfer were determined from the generated voltammograms and were found to be $1.40 \times 10^{-5} \mathrm{~m} / \mathrm{s}$ and $2.50 \times 10^{-5} \mathrm{~m} / \mathrm{s}$, respectively ${ }^{14}$. In addition, the values of standard redox potentials $\left(E_{1}^{\bullet}\right.$ and $\left.E_{2}^{\ominus}\right)$ were $0.065 \mathrm{~V}$ and $0.115 \mathrm{~V}$ for the first and second electron transfer, respectively. The values of $D_{1}$ and $D_{2}$ were $5.40 \times 10^{-9} \mathrm{~m}^{2} / \mathrm{s}$ and $5.85 \times 10^{-9} \mathrm{~m}^{2} / \mathrm{s}$, 


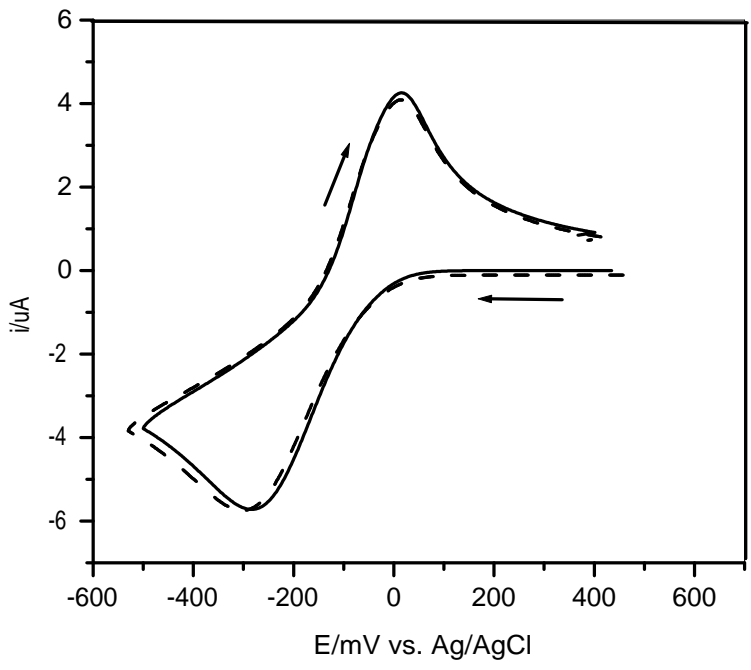

Fig. 2 Matching between experimental voltammogram of $\mathrm{Cu}$ (II) (solid line) and simulated voltammogram (dashed line) at a sweep rate of $0.2 \mathrm{~V} / \mathrm{s}$.

respectively; and the values of symmetry transfer coefficient $\alpha_{1}$ and $\alpha_{2}$ were 0.31 and 0.30 , respectively.

It was found that the plot of $i_{\mathrm{p}}$ versus $\sqrt{v}$ produced a nonlinear curve, indicating that the reaction deviates from the behaviour of two onestep electron transfers. This behaviour confirmed the presence of two sequential electron transfer steps. Fig. 2 shows the experimental and theoretical calculations of the electrochemical parameters for $\mathrm{Cu}$ (II) ions; clearly the results demonstrate good agreement between the captured data and the simulated data.

The mechanism proposed here was confirmed and verified by generating the following simulated cyclic voltammograms: (i) $E_{n=1} E_{n=1}$ scheme using the values of calculated electrochemical parameters at different values of separation between the first and the second redox potentials $\left(\Delta E^{\prime \bullet}\right)$. The values selected for $\Delta E^{\ominus}$ are $100 \mathrm{mV}, 150 \mathrm{mV}, 200 \mathrm{mV}$, $250 \mathrm{mV}, 300 \mathrm{mV}$, and $350 \mathrm{mV}$ (Fig. 3), and (ii) $E_{n=2}$ scheme, where $n$ is the number of electron transfer and the symbol $E$ refers to the electron transfer.

It the case of the EE scheme, when $\Delta E^{\prime \theta} \geqslant$ $100 \mathrm{mV}$, there is a disagreement between the experimental voltammograms and the theoretical voltammograms which confirms the proposed mechanism. In addition, in the case of simple electron transfer ( $E_{n=2}$ scheme), there is a large deviation between the experimental voltammogram of bivalent $\mathrm{Cu}$ (II) and the generated cyclic voltammogram of $E_{n=2}$
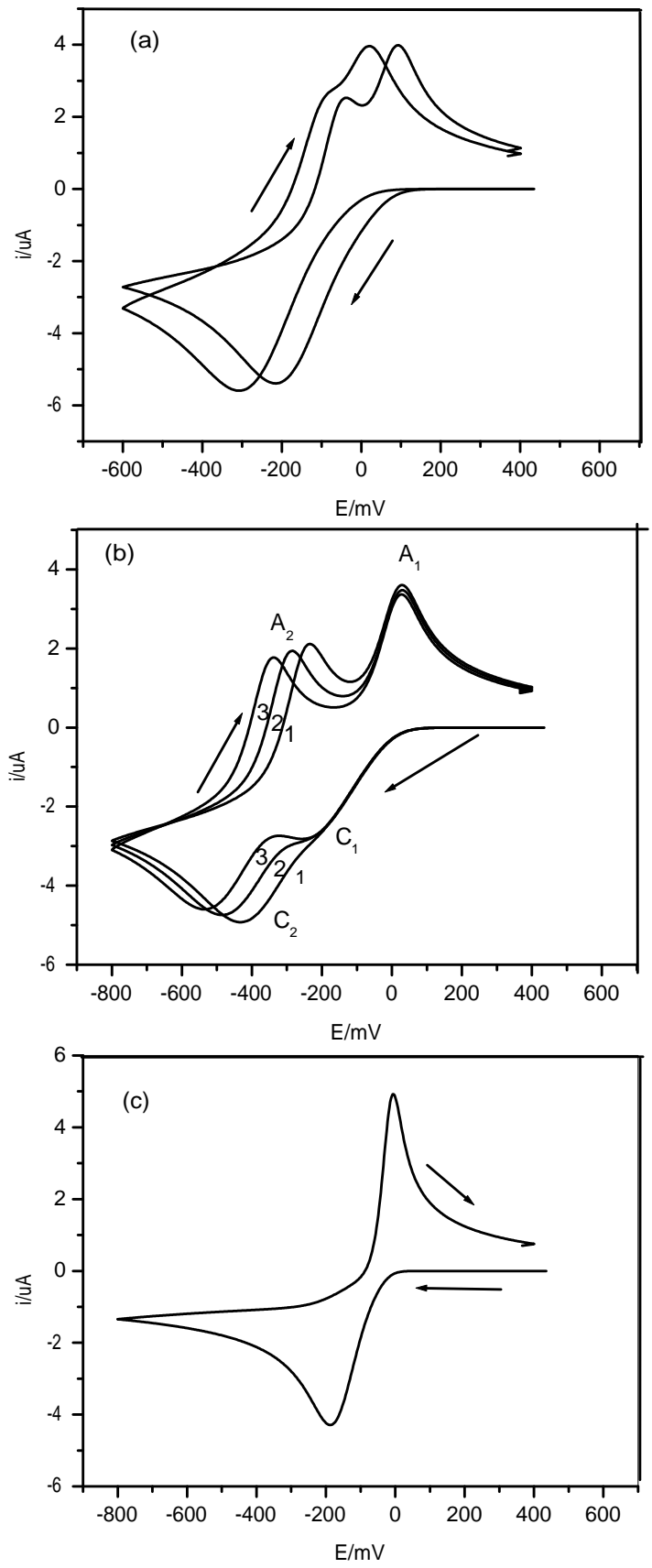

Fig. 3 Simulated cyclic voltammograms of EE scheme when (a) $\Delta E^{\prime \theta}=100 \mathrm{mV}$ and $150 \mathrm{mV}$; (b) $\Delta E^{\prime \theta}=$ $250 \mathrm{mV}, 300 \mathrm{mV}$, and $350 \mathrm{mV}$, labelled 1, 2, and 3, respectively; and (c) $\Delta E^{\prime \ominus}=0.0$.

scheme (Fig. 3).

In the case of sequential two-charge transfer processes, there are two activation barriers. The free energy of the activated complex of the first step $\left(\Delta G^{\#}\right)$ can be calculated from the standard 


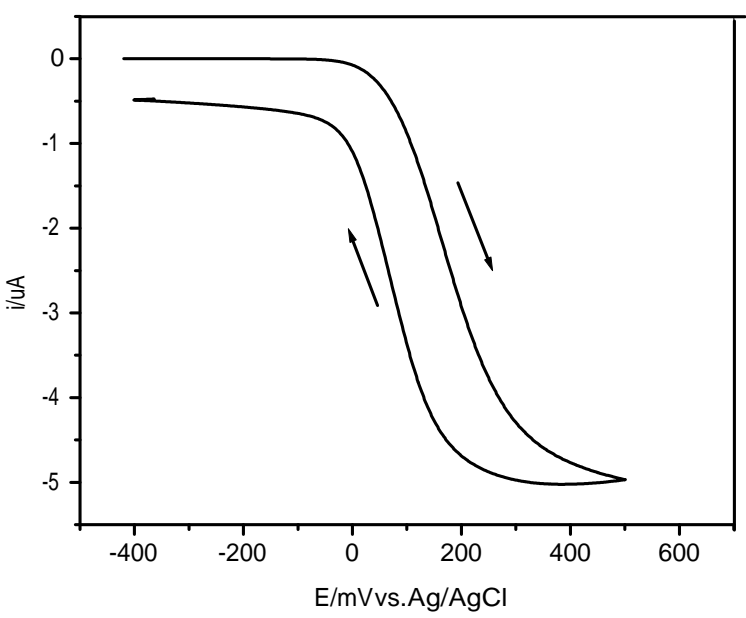

Fig. 4 Convolution voltammetry $\left(I_{1}\right)$ of the reductive process of $\mathrm{Cu}$ (II) ion sweep rate of $0.2 \mathrm{~V} / \mathrm{s}$.

heterogeneous electron transfer using the following equation $^{15,16}$ :

$$
\Delta G_{\text {exp }}^{\#}=0.05915\left(4-\log k^{\ominus}\right) \mathrm{eV} \text { at } 298 \mathrm{~K} .
$$

It was found that the value of $\Delta G^{\#}$ was $9.08 \mathrm{~J} / \mathrm{mol}$ for the first electron transfer.

\section{Convolution transforms}

The following equation defines $I_{1}$ convolution $^{17,18}$ :

$$
I_{1}(t)=\frac{1}{\sqrt{\pi}} \int_{0}^{t} \frac{i(u)}{\sqrt{t-u}} \mathrm{~d} u .
$$

It is used for the electroactive species diffusion coefficient determination using $^{17}$ :

$$
I_{\lim }=\left(n_{1}+n_{2}\right) F A C \sqrt{D},
$$

where $I_{\text {lim }}$ is the limiting convoluted current of $I_{1}$, $n_{1}$ and $n_{2}$ are the number of electrons transferred, $F$ is the Faraday constant $(96500 \mathrm{C} / \mathrm{mol}), A$ is the electrode surface area, $C$ is the bulk concentration of electroactive species, and $D$ is the diffusion coefficient $\left(\mathrm{m}^{2} / \mathrm{s}\right)$. The calculated value of the diffusion coefficient $(D)$ via (1) is equal to $5.1 \times 10^{-9} \mathrm{~m}^{2} / \mathrm{s}$. The $I_{1}$ convolution of $\mathrm{Cu}(\mathrm{II})$ at $0.2 \mathrm{~V} / \mathrm{s}$ scan rate is shown in Fig. 4.

The curve in Fig. 4 exhibits a separation between the forward and the reverse sweep of the $I_{1}$ convolution, and the reverse sweep of $I_{1}$ convolution does not return to zero, which might be attributed to amalgam formation and confirming two sequential electron transfer mechanism with moderate speed of the rate of two electron transfer

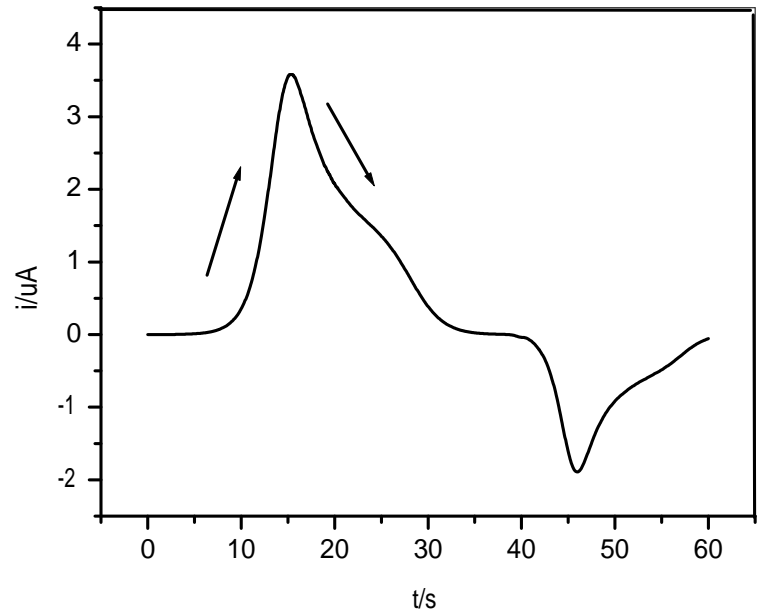

Fig. 5 Plot of $i$ versus $t$ corresponding to a reductive cyclic voltammogram at the sweep rate of $0.2 \mathrm{~V} / \mathrm{s}$. The point $t=$ $25.4 \mathrm{~s}$ is the time at which the potential scan is switched to the reverse direction.

between the HMDE and Cu(II) ion, i.e., moderately fast EE mechanism followed by amalgam formation.

For an electron transfer in the case of a quasireversible reaction, the equation is adapted ${ }^{19}$ to:

$E=E^{\ominus}+\frac{R T}{\alpha n F} \ln \left(\frac{k^{\ominus}}{i \sqrt{D}}\left(I_{\lim }-I\left(1+\mathrm{e}^{(n F / R T)\left(E-E^{\ominus}\right)}\right)\right)\right)$.

Thus in the case of simple electron transfer ( $E$ scheme) the presentation of

$$
\ln \left(\frac{1}{i}\left(I_{\lim }-I\left(1+\mathrm{e}^{(n F / R T)\left(E-E^{\bullet}\right)}\right)\right)\right) \text { versus } E
$$

gives a straight line with the slope of $\alpha n F / R T$. Hence a nonlinearity of the plot confirms the presence of two quasi-reversible electron transfer (EE) mechanism with close values of two redox potential in the investigated system.

Fig. 5 shows the plot of $i$ versus $t$ of the voltammogram at the scan speed of $0.2 \mathrm{~V} / \mathrm{s}$. The exhibited discontinuity $\Delta i_{\mathrm{c}}$ at $t=25.4 \mathrm{~s}$ is due to the reversibility of the scan. The Cottrell plot is presented as $i$ versus $1 / \sqrt{t}$. The slope of the $i$ versus $1 / \sqrt{t}$ plot yields a diffusion coefficient $D=5.4 \times 10^{-9} \mathrm{~m}^{2} / \mathrm{s}$. Clearly from Fig. 5 the height ratio of the forward peak to the reverse peak is different from the one confirming the existence of amalgam formation ${ }^{13}$.

\section{Deconvolution transforms}

The deconvolution transforms $\left(\mathrm{d} I_{1} / \mathrm{d} t\right)$ as a function of $E$ of reversible electrode process is defined 


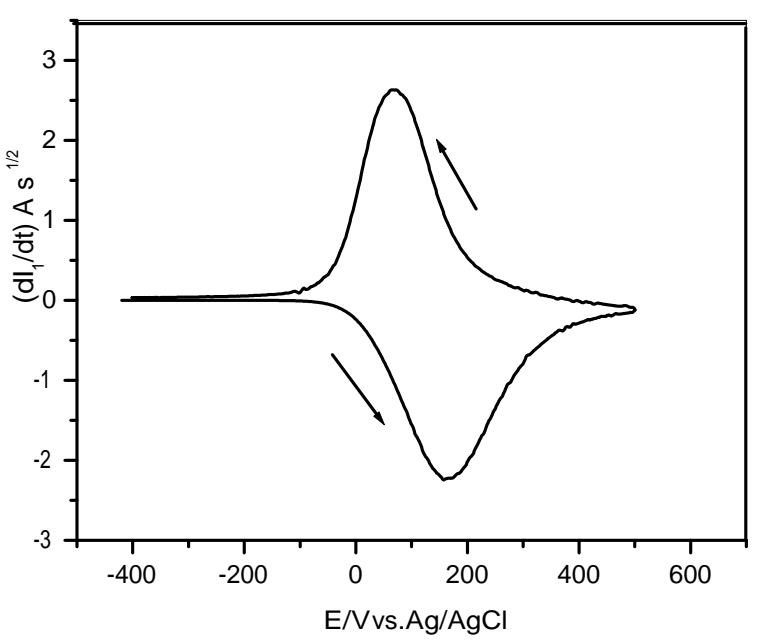

Fig. 6 Deconvolution voltammetry $\left(\mathrm{d} I_{1} / \mathrm{d} t\right)$ of the reductive cyclic voltammogram of $\mathrm{Cu}(\mathrm{II})$ at a sweep rate of $0.2 \mathrm{~V} / \mathrm{s}$.

as $^{12}$ :

$$
e_{\mathrm{p}}=\frac{\mathrm{d}^{1 / 2} i}{\mathrm{~d} t^{1 / 2}}=\frac{\mathrm{d} I_{1}}{\mathrm{~d} t}=\left(n_{1}+n_{2}\right) F A C \sqrt{D} a \frac{\zeta}{(1+\zeta)^{2}}
$$

in which the parameters $a$ and $\zeta$ are defined as

$$
\begin{aligned}
a & =\frac{n v F}{R T}, \\
\zeta & =\exp \left(\frac{n F}{R T}\left(E-E^{\ominus}\right)\right) .
\end{aligned}
$$

The image of $\mathrm{d} I_{1} / \mathrm{d} t$ produces two peaks with a maximum and minimum amplitude alignment at $E_{1 / 2}$ values in the case of rapid electron transfer and $T=298 \mathrm{~K}$. A plot of (2) using $v=0.2 \mathrm{~V} / \mathrm{s}$ in $0.1 \mathrm{M}$ $\mathrm{KNO}_{3}$ is shown in Fig. 6. The peak width of deconvolution $W^{\mathrm{p} / 2}$ in the case of fast electron transfer is equal to $3.53 R T / n F=90.5 / n \mathrm{mV}$. In this communication, the measured $W^{\mathrm{p} / 2}=211 \pm 2 \mathrm{mV}$, confirming the quasi-reversibility of the charge transfer.

Moreover, the asymmetry and the deviation from the alignment point of the forward and the backward sweep confirm the quasi-rapidity of both charge transfer of the electroreduction $\mathrm{Cu}$ (II) ions process. The peak height was also proportional to $\mathrm{Cu}$ (II) concentration, to the area of electrode surface, to the number of electrons, and to the scan speed $v$. It was found that the convolutive and deconvolutive voltammetry curves were much easier to understand and to interpret than the cyclic voltammetry curves.

In addition, the diffusion coefficient $(D)$ values were calculated using the following relationship ${ }^{13}$ :

$$
I_{\lim , \mathrm{d}}=\frac{i_{\mathrm{p}}}{3.099 \sqrt{\alpha n_{\mathrm{a}} v}},
$$

where $I_{\text {lim,d }}$ is the limiting convoluted current deduced from CV and $I_{1}, i_{\mathrm{p}}$ is the peak current of the quasi-reversible electrode reaction, $n_{\mathrm{a}}$ is the number of electrons participating in the rate determining step, and $v$ is the scan rate. The values of $D$ calculated from $I_{\text {lim,d }}$ agree well with those calculated from the convolution voltammetry and the digital simulation.

In addition, a simple and accurate method to calculate the number of electrons consumed in the electrode reaction ${ }^{13}$ is

$$
n=\frac{0.086 e_{\mathrm{p}}}{I_{\lim } \alpha v},
$$

where $e_{\mathrm{p}}$ is the height of deconvoluted peak current and the other symbols have their usual meaning. The calculated number of electrons $\left(n=n_{1}+n_{2}\right)$ was found to be 2.05 for the overall reduction process.

In this work, the first-order derivative voltammetry $\left(\mathrm{e}^{-}\right)$is presented. This method exhibits high sensitivity, resolution, reproducibility, and rapidity of the system. The presentation of $\mathrm{e}^{-}$versus $E$ calculated by G1 algorithms for electroreduction of $\mathrm{Cu}$ (II) ion at the scan speed of $0.2 \mathrm{~V} / \mathrm{s}$ indicates that the height of the forward peak increases with an increase in the scan rate and the position of peak potential shifted to more cathodic potential. This behaviour agrees well with cyclic voltammetry and deconvoluted voltammetry, and indicates that the quasi-reversible nature of the two electron transfer involved in the electroreduction of bivalent $\mathrm{Cu}$ (II) ion closely with two redox potentials.

From this study, it can be concluded that the redox potential for the first reduction process is slightly less negative than the second one, which shows that the first process requires less energy than the second one.

\section{Chronoamperometric study}

Stepping the potential from an initial potential $\left(E_{\mathrm{i}}\right)$ to a final one $\left(E_{\mathrm{f}}\right)$, and recording the current as a function of time are the basis of chronoamperometry experiment. Chronoamperogram of $2.5 \times 10^{-4} \mathrm{M}$ solution of the $\mathrm{Cu}$ (II) ion in $0.1 \mathrm{M} \mathrm{KNO}_{3}$ at HMDE, with $E_{\mathrm{i}}=-0.05 \mathrm{~V}$ and $E_{\mathrm{f}}=-0.25 \mathrm{~V}$, is shown in Fig. 7. The forward rate constant $k_{\mathrm{f}}$ was determined via the following equation ${ }^{14}$ :

$$
i(t)=-\beta I_{1}+u,
$$




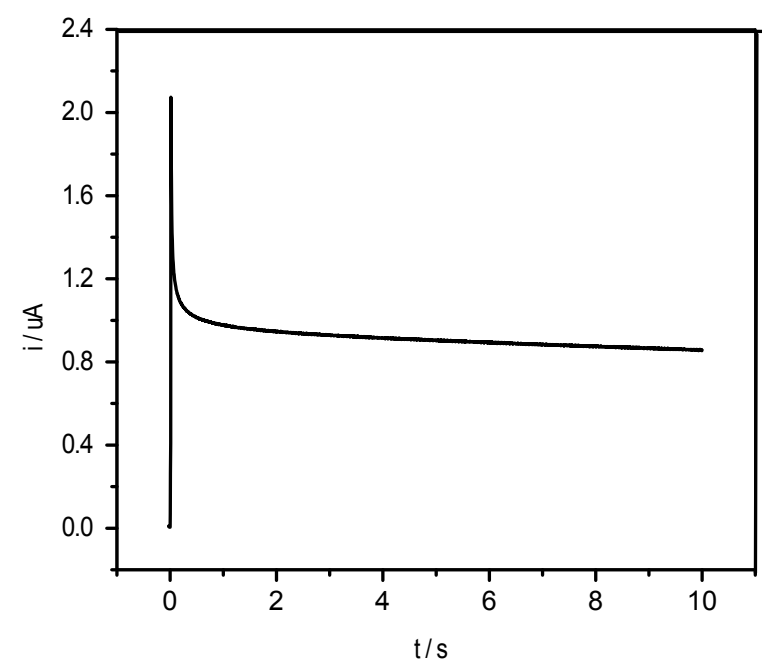

Fig. 7 Chronoamperogram of $2.5 \times 10^{-4} M$ of bivalent $\mathrm{Cu}(\mathrm{II})$ ion in $0.1 \mathrm{M} \mathrm{KNO}_{3}$.

where $u=\left(n_{1}+n_{2}\right) F A C k_{\mathrm{f}} \sqrt{D}$ and $\beta=k_{\mathrm{f}} \sqrt{D}$. The slope of the linear plot of $i(t)$ versus $I_{1}$ and the intercept at $I_{1}=0$ produce the value of $k_{\mathrm{f}}$.

Here the correlation between the rate constant $\left(k_{\mathrm{f}}\right)$, the electrode potential $(E)$, and the electron transfer is investigated by the Butler-Volmer treatment using the equation ${ }^{14}$ :

$$
\log k_{\mathrm{f}}=\frac{\alpha n F}{R T}\left(E_{\mathrm{f}}-E^{\prime \ominus}\right)+\log k^{\ominus} .
$$

The slope of the linear plot for $\log k_{\mathrm{f}}$ versus $E_{\mathrm{f}}-E^{\prime \ominus}$ gives an $\alpha$ value of 0.34 . The standard heterogeneous rate constant $k^{\ominus}$ value was found to be $2.65 \times 10^{-5} \mathrm{~m} / \mathrm{s}$ from the point at which $E_{\mathrm{f}}=E^{\ominus}$. Both values agreed well with those calculated from the digital simulation and the cyclic voltammetric data.

\section{Chronopotentiometric investigation}

Solution of $2.5 \times 10^{-4} \mathrm{M}$ of $\mathrm{Cu}(\mathrm{II})$ in $0.1 \mathrm{M} \mathrm{KNO}_{3}$ at HMDE displayed chronopotentiogram with only one reduction transition time in agreement with the result obtained from cyclic voltammetry. The following equation was used to analyse the chronopotentiometric transition time ${ }^{18}$ :

$$
I_{\lim }=2 i_{\mathrm{c}} \sqrt{\frac{t_{\mathrm{s}}}{\pi}}=\left(n_{1}+n_{2}\right) F A C \sqrt{D},
$$

where $i_{\mathrm{c}}$ is the polarization current, $t_{\mathrm{s}}$ is the transition time of the bivalent $\mathrm{Cu}(\mathrm{II})$, and the remaining terms have their usual meaning. The value of the diffusion coefficient $D$ calculated from chronopotentiometry compares well with that obtained from each of $I_{1}$ convolution, deconvolution voltammetry, and digital simulation methods.

According to the above discussion, the reductive electrode behaviour of bivalent $\mathrm{Cu}$ (II) ion can be suggested to proceed as

$$
\mathrm{Cu}(\mathrm{II})+\mathrm{e}^{-} \longleftrightarrow \mathrm{Cu}(\mathrm{I})+\mathrm{e}^{-} \longleftrightarrow \mathrm{Cu}(\mathrm{Hg}),
$$

i.e., EE mechanism with copper amalgam formation process.

\section{CONCLUSIONS}

In this article, the electrochemical behaviour of bivalent $\mathrm{Cu}(\mathrm{II})$ ion was investigated at HMDE in $0.1 \mathrm{M} \mathrm{KNO}_{3}$ using cyclic voltammetry combined with convolutive voltammetry, chronoamperometry, and chronopotentiometry techniques. The results of this study summarize the reports of electrochemical studies of $\mathrm{Cu}$ (II) ion and show that the electrode process of $\mathrm{Cu}(\mathrm{II})$ ion in $0.1 \mathrm{M} \mathrm{KNO}_{3}$ at a mercury electrode proceeds as two consecutive electron transfer and produces one broad reductive peak coupled with one broad anodic peak. This behaviour indicates that the first charge transfer produces a univalent $\mathrm{Cu}(\mathrm{I})$ ion that accepts another electron to gives $\mathrm{Cu}$ metal which combines with mercury to form $\mathrm{Cu}(\mathrm{Hg})$. The kinetic parameters calculated experimentally were confirmed using a digital simulation method.

Acknowledgements: This project was supported by King Saud University, Deanship of Scientific Research, College of Science Research Centre.

\section{REFERENCES}

1. Dollwet HHA, Sorenson JRJ (1985) Historic uses of copper compounds in medicine. Trace Elem Med 2, 80-7.

2. Weder JE, Dillon CT, Hambley TW, Kennedy BJ, Lay PA, Biffin JR, Regtop HL, Davies NM (2002) Copper complexes of non-steroidal anti-inflammatory drugs: an opportunity yet to be realized. Coord Chem Rev 232, 95-126.

3. Bharti SK, Singh SK (2009) Metal based drugs: Current use and future potential. Pharm Lett 1(2), 39-51.

4. Kastenholz B (2006) Comparison of the electrochemical behavior of the high molecular mass cadmium proteins in Arabidopsis thaliana and in vegetable plants on using preparative native continuous polyacrylamide gel electrophoresis (PNC-PAGE). Electroanalysis 18, 103-6.

5. Kastenholz B (2007) New hope for the diagnosis and therapy of Alzheimer's disease. Protein Pept Lett 14, 389-93. 
6. Motin MA, Rahman MM, Hafiz Mia MA, Salim Reza KM, Aziz MA, Hashem MA (2015) Voltammetric study of $\mathrm{Cu}(\mathrm{II})$ in presence of aspartic acid and L-phenyl alanine at different $\mathrm{pH}$ media. Anal Bioanal Electrochem 7, 264-76.

7. Samide MJ, Peters DG (1998) Electrochemical reduction of copper(II) salen at carbon cathodes in dimethylformamide. J Electroanal Chem 443, 95-102.

8. Shaikh AA, Firdaws J, Badrunnessa Serajee S, Rahman MS, Bakshi PK (2011) Electrochemical studies of the $\mathrm{pH}$ dependence of $\mathrm{Cu}(\mathrm{II})$ reduction in aqueous Britton-Robinson buffer solution. Int $J$ Electrochem Sci 6, 2333-43.

9. Aravinda CL, Mayanna SM, Muralidharan VS (2000) Electrochemical behaviour of alkaline copper complexes. Proc Indian Acad Sci Chem Sci 112, 543-50.

10. Kolthoff IM, Okinaka Y (1959) Effects of surface active substances on polarographic waves of copper(II) Ions. J Am Chem Soc 81, 2296-302.

11. Bard AJ, Faulkner LR (1980) Electrochemical Methods, Fundamentals and Applications, Wiley, New York.

12. Dalrymple-Alford P, Goto M, Oldham KB (1977) Peak shapes in semi-differential electroanalysis. Anal Chem 49, 1390-4.

13. El-Daly SA, El-Hallag IS, Ebeed EM, Ghoneim MM (2009) Electrochemical studies of 1,4-bis[2(2-pyridyl)-vinyl] benzene and 1,4-bis[2-(4-pyridyl) vinyl] benzene laser dyes via cyclic voltammetry, convolutive voltammetry and digital simulation methods. Chin J Chem 27, 241-7.

14. El-Hallag IS, Hassanien AM (1999) Electrochemical studies of the complex (OC-6-22)-W(CO) ${ }_{3}(\mathrm{dppm})_{2}$ at a glassy carbon electrode in $\mathrm{CH}_{2} \mathrm{Cl}_{2}$. Collect Czech Chem Comm 64, 1953-65.

15. Nicholson RS, Shain I (1965) Theory of stationary electrode polarography. Anal Chem 37, 1351-5.

16. Hale JM (1971) The rates of reactions involving only electron transfer, at metal electrodes. In: Hush NS (ed) Reactions of Molecules at Electrodes, Wiley Interscience, New York, pp 229-58.

17. Tsierkezos NG (2007) Investigation of the electrochemical reduction of benzophenone in aprotic solvents using the method of cyclic voltammetry. $J$ Solut Chem 36, 1301-10.

18. El-Hallag IS, Hassanein AM, Ghoneim MM (1995) Electrochemical study of the hetero-bimetallic complex $\left[\mathrm{MeNC}(\mathrm{CO})_{2} \mathrm{Mn}(\mathrm{dppm})_{2} \mathrm{Pt}(\mathrm{H})(\mathrm{CNMe})\right]^{+} \mathrm{PF}_{6}{ }^{-}$ at a glassy carbon electrode. Monatsh Chem Chem Mon 126, 1075-85.

19. Ammar F, Savéant JM (1973) Convolution potential sweep voltammetry: II. Multistep nernstian waves. $J$ Electroanal Chem 47, 215-21. 